\title{
INTERAÇÃO ENTRE FUNGOS MICORRÍZICOS ARBUSCULARES E ÁCIDO INDOLBUTÍRICO SOBRE O DESENVOLVIMENTO VEGETATIVO DE PLÂNTULAS DO PORTA-ENXERTO DE PESSEGUEIRO 'ALDRIGHI'
}

\author{
Effect of arbuscular mycorrhizal fungi and indolebutyric acid interaction on \\ vegetative growth of 'Aldrighi' peach rootstock seedlings
}

\author{
José Luis da Silva Nunes ${ }^{1}$, Paulo Vitor Dutra de Souza², \\ Gilmar Arduino Bettio Marodin ${ }^{3}$, José Carlos Fachinello ${ }^{4}$
}

\begin{abstract}
RESUMO
Objetivou-se, neste trabalho, avaliar o efeito da interação entre três espécies de fungos micorrízicos arbusculares (FMAs) (Gigaspora margarita W.N. Becker \& I.R. Hall., Glomus clarum Nicol \& Schenck e Glomus etunicatum Becker \& Gerd) e a aplicação radicular de ácido indolbutírico (AIB; 1,5 g.L.-1) sobre o crescimento vegetativo e nutrição mineral de mudas do porta-enxerto de pessegueiro (Prunus persica) cv. Aldrighi. Foi utilizado o delineamento experimental de blocos ao acaso, com oito tratamentos, quatro repetições por tratamento e dez plantas por parcela. A aplicação do AIB não alterou o desenvolvimento vegetativo das plantas cultivadas em ausência de FMAs, apesar de aumentar a quantidade de potássio nos tecidos. Glomus clarum e Glomus etunicatum incrementaram o crescimento vegetativo e o conteúdo de nitrogênio, fósforo e potássio dos tecidos das plantas. Plantas inoculadas com FMAs, ao serem tratadas com AIB, apresentaram incremento no desenvolvimento vegetativo e nos conteúdos nutricionais, comparativamente àquelas não tratadas com a auxina.
\end{abstract}

Termos para indexação: AIB, Prunus persica, endomicorrizas, propagação.

\begin{abstract}
The objective of this work was to evaluate the effect of the interaction between three arbuscular mycorrhizal fungi (AMFs) species (Gigaspora margarita W.N. Becker \& I.R. Hall., Glomus clarum Nicol \& Schenck and Glomus etunicatum Becker \& Gerd) and the rooting application of indolebutyric acid (IBA; 1,5 g. $\mathrm{L}^{-1}$ ) on the vegetative growth and shoot mineral nutrition on peach tree rootstock (Prunus Persica) seedlings cv. Aldrighi. Random block delineation was used, with eight treatments, four repetitions per treatment and ten plants per plot. The application of IBA didn't alter the vegetative development of the plants cultivated in absence of AMFs, in spite of having increased the amount of potassium. Glomus clarum and Glomus etunicatum increased the vegetative growth and the nitrogen, phosphorus and potassium shoot contents of the inoculated plants. Inoculated plants treated with IBA presented a increment in vegetative development and shoot nutritional contents compared to those cultivated in absence of IBA.
\end{abstract}

Index terms: IBA, Prunus persica, endomycorrhizae, plant propagation.

(Recebido em 10 de agosto de 2007 e aprovado em 16 de fevereiro de 2009)

\section{INTRODUÇÃO}

Fungos micorrízicos arbusculares (FMAs) são organismos que se associam às raízes das plantas, incrementando a absorção nutricional e estimulando o crescimento destas (Souza et al., 2000). Os benefícios dessa simbiose devem-se a fatores nutricionais, principalmente ao aumento da absorção de nitrogênio (Souza et al., 2005), fósforo e potássio (Calvet et al., 2003). Além de melhorar o estado nutricional das mudas, os FMAs aceleram o crescimento e melhoram o vigor das mesmas na sua fase de formação (Calvet et al., 2003; Souza et al., 2005). Respostas de crescimento vegetal como consequência direta da inoculação com FMAs foram relatadas em portaenxertos de diversas espécies frutíferas, como pessegueiro (Calvet et al., 2003), macieira (Locatelli \& Lovato, 2002), e citros (Souza, 2000; Souza et al., 2000, 2005).

O complexo mecanismo pelo qual essa simbiose é regulada exige uma contínua troca dos sinais, que conduz ao desenvolvimento apropriado da simbiose (Kaldorf \& Ludwig-Müller, 2000). Os fito-hormônios são moléculas sinalizadoras que regulam muitos processos de

\footnotetext{
${ }^{1}$ Faculdade de Agronomia, UFRGS - Rua Silvio Silveira Soares - 2406/130 - Bairro Camaquã - Porto Alegre, RS - $91910-460$ - silva.nunes@ufrgs.br ${ }^{2}$ Faculdade de Agronomia, UFRGS - Departamento de Horticultura e Silvicultura - Porto Alegre, RS

${ }^{3}$ Faculdade de Agronomia, UFRGS - Departamento de Horticultura e Silvicultura - Porto Alegre, RS

${ }^{4}$ Faculdade de Agronomia Eliseu Maciel, UFPel - Departamento de Fitotecnia - Pelotas, RS
} 
desenvolvimento das plantas (Fitze et al., 2005), sendo considerados, também, como fundamentais no processo da colonização pelos FMAs (Barker \& Tagu, 2000). Kaldorf \& Ludwig-Müller (2000) observam que plantas colonizadas por FMAs apresentam incremento na biossintese e na concentração de ácido idol-3-butírico (IBA) livre nas suas raízes, ao mesmo tempo em que essas apresentam significativo aumento na sua ramificação lateral. Segundo os mesmos autores, o incremento dos porcentuais de AIB estaria relacionado com o aumento da interação entre a planta e os FMAs. Conforme Ludwig-Müller (2000), apesar de a síntese da fito-hormônios em plantas colonizadas por FMAs ainda ser pouco estudada, há evidências de que o intercâmbio hormonal entre os FMAs e as plantas hospedeiras existe.

Hartmann et al. (2001) relatam que a maioria das plantas superiores não responderiam a aplicação de AIB na fase de elongação radicular, em virtude de uma rápida metabolização do AIB nas raízes, originando um derivado inativo. Porém, segundo Souza et al. (2000), a aplicação exógena de AIB durante a fase de elongação radicular, em plantas colonizadas por FMAs, promoveria um incremento na ramificação lateral das raízes e o aumento da colonização das mesmas, indicando uma sensibilidade das endomicorizas à aplicação da auxina.

Objetivou-se, neste trabalho, avaliar o efeito da interação entre a inoculação de três espécies de FMAs e a aplicação de AIB na fase de elongação celular nas raízes, sobre o desenvolvimento vegetativo e os teores de macronutrientes em plantas do porta-enxerto cv. Aldrighi.

\section{MATERIAL E MÉTODOS}

O experimento foi iniciado em 21 de outubro de 2005 e foi conduzido por doze meses em casa de nebulização com sistema de irrigação por aspersão, no setor de Horticultura da Estação Experimental Agronômica (EEA) da Universidade Federal do Rio Grande do Sul (UFRGS), Km 146 da BR 290, município de Eldorado do Sul, RS.

O delineamento experimental utilizado foi o de blocos casualizados, com oito tratamentos, em esquema fatorial de $2 \times 4$ (tratamentos com e sem AIB, três com inoculação de FMAs - Gigaspora margarita, Glomus clarum e Glomus etunicatum - e um tratamento testemunha não inoculado), quatro repetições por tratamento e 10 plantas por repetição.

Caroços do porta-enxerto de pessegueiro cv. Aldrighi foram estratificados em caixa plástica (40 cm x $28 \mathrm{~cm}$ x $10 \mathrm{~cm}$ ) contendo areia e colocados, por um período de 45 dias, em geladeira à temperatura de $4^{\circ} \mathrm{C}$, visando interromper a dormência do embrião e facilitar a germinação.
A areia foi previamente autoclavada a $120^{\circ} \mathrm{C}$ por uma hora. Logo após o período de estratificação, as amêndoas foram retiradas dos caroços e semeadas em caixas plásticas semelhantes às anteriores, preenchidas com areia desinfestada e mantidas em casa de nebulização. No momento da semeadura procedeu-se a adição dos inóculos contendo estruturas (hifas e esporos) das espécies de FMAs ao substrato (30 gramas por recipiente, 10 esporos por grama de inóculo), em uma camada situada na altura intermediária de cada recipiente. $\mathrm{O}$ inóculo era constituído de raízes e solo rizósférico de braquiária (Brachiaria decumbens Stapf), espécie vegetal utilizada para multiplicar, por cultivo monospórico, cada uma das espécies de FMAs. Os esporos foram isolados a partir de amostras de solo, coletadas em pomares de pessegueiro da coleção da EEAUFRGS, através do método de lavagem, decantação, peneiramento e centrifugação (Gerdemann \& Nicolson, 1963), e a identificação das espécies foi realizada segundo Schenck \& Perez (1988).

Trinta dias após a semeadura as plântulas foram repicadas para sacos plásticos pretos (5 litros) contendo substrato constituído de terra argilosa oriunda de um solo Argissolo Vermelho distrófico típico (Embrapa, 1999), areia (granulometria entre 0,6 e $1 \mathrm{~mm}$ ) e resíduo decomposto de casca de acácia negra (1:1:1, V:V.V). O substrato apresentou, em 21/10/2005, a seguinte caracterização química: $4,8 \%$ de matéria orgânica, pH 5,2, 7,9 mg.dm ${ }^{-3}$ de fósforo, $59 \mathrm{mg} . \mathrm{dm}^{-}$ ${ }^{3}$ de potássio, $4,2 \mathrm{cmol} . \mathrm{L}^{-1}$ de cálcio e $2,2 \mathrm{cmol}$. $\mathrm{L}^{-1} \mathrm{de}$ magnésio. O substrato foi previamente desinfestado com solução de formaldeído a 10\%, não tendo sido feita correção e nem fertilização do mesmo. Nesse momento o sistema radicular das plântulas foi imerso em solução hidroalcoólica contendo uma concentração de 1,5 g. $\mathrm{L}^{-1}$ de ácido indolbutírico (AIB) por um período de 10 segundos. As raízes das plantas testemunhas, nas quais não foi usado o AIB, foram imersas pelo mesmo período em água destilada.

Doze meses após a semeadura, mediu-se a altura e o diâmetro do colo das plantas. Após, as plantas foram colhidas para as determinações de área foliar, através do uso de medidor de área foliar marca Li-Cor (modelo LI 3000), biomassas fresca e seca da parte aérea, teores de macronutrientes da parte aérea (folhas e hastes), segundo o método de Tedesco et al. (1995), colonização radicular com FMA (relação: número de segmentos infectados/total analisado) e avaliação da presença e intensidade de hifas (índices: 0 - ausência; 1 - presença fraca; 2 - moderada; 3 intensa), vesículas e arbúsculos (índices: 0 - ausência; 1 1 a 50 estruturas; 2 - 51 a 100 estruturas; 3 - mais de 100 estruturas por $\mathrm{cm}$ de radicela), segundo método descrito por Nemec (1992). 
Os dados foram submetidos à análise de variância executada pelo programa SAS e as médias foram comparadas pelo teste de Duncan, ao nível de 5\% de significância.

\section{RESULTADOS E DISCUSSÃO}

Os FMAs foram eficientes em incrementar a altura e o diâmetro do colo das plantas, com exceção do tratamento com G. margarita sem aplicação de AIB, que não diferiu da testemunha (Tabela 1).

Dentre as espécies de FMAs, G. etunicatum promoveu incremento de $16,7 \%$ em altura e $7,52 \% \mathrm{em}$ diâmetro em relação a $G$. clarum e este promoveu incrementos de $11 \%$ em altura e 9,6\% em diâmetro quando feita a comparação com G. margarita. A aplicação do AIB não modificou a altura e o diâmetro do colo das plantas testemunhas, mas ocorreu interação entre o efeito dos FMAs e do AIB, potencializando o incremento proporcionado por $G$. etunicatum em $41,6 \%$ para altura e $20,91 \%$ para o diâmetro, por G. clarum em 32,34\% para altura e 17,4\% para o diâmetro e por G. margarita em 12,8\% para altura e $11,42 \%$ para diâmetro, quando feita a comparação com as testemunhas. Esses resultados são coincidentes aos obtidos por Souza (2000) e Souza et al. (2000) que, ao trabalharem com citrange Carrizo, verificaram que a aplicação de auxinas em plântulas inoculadas com FMAs incrementou a altura e o diâmetro das mesmas em até $50 \%$ em relação a plântulas não inoculadas. Ferrol et al. (2002), relatam que o aumento da concentração de AIB em raízes colonizadas proporciona um aumento na interface FMA - planta, aumentando a superfície de transferência de água e nutrientes, principalmente fosfatos, que serão usados na fotossíntese e que, em última instância, acaba por promover incremento no desenvolvimento vegetal. Além disso, a aplicação exógena de auxinas incrementa o desenvolvimento das ramificações laterais das raízes, aumentando a área de exploração do solo pela planta (Ludwig-Müller, 2000).

Houve interação entre o efeito dos FMAs e do AIB sobre a área foliar e a biomassa fresca e seca. Os FMAs incrementaram a área foliar e a biomassa fresca das plantas, exceto às inoculadas com $G$. margarita sem aplicação de AIB, que não diferiram da testemunha. Todos os FMAs propiciaram aumentos da biomassa seca em relação à testemunha (Tabela 2).

Tabela 1 - Altura e diâmetro do colo de plantas do porta-enxerto de pessegueiro cv. Aldrighi inoculadas com três espécies de FMAs e tratadas com AIB, 360 dias após a semeadura. Eldorado do Sul, RS, $2006^{1}$.

\begin{tabular}{lcccc}
\hline \multirow{2}{*}{ Tratamentos } & \multicolumn{2}{c}{ Altura $(\mathrm{cm})$} & \multicolumn{2}{c}{ Diâmetro $(\mathrm{mm})$} \\
\cline { 2 - 5 } & + AIB & - AIB & + AIB & - AIB \\
\hline G. margarita & $150,00 \mathrm{cA}$ & $132,00 \mathrm{cB}$ & $6,93 \mathrm{cA}$ & $6,20 \mathrm{cB}$ \\
G. clarum & $176,00 \mathrm{bA}$ & $146,53 \mathrm{bB}$ & $7,31 \mathrm{bA}$ & $6,79 \mathrm{bB}$ \\
G. etunicatum & $188,33 \mathrm{aA}$ & $171,00 \mathrm{aB}$ & $7,52 \mathrm{aA}$ & $7,30 \mathrm{aB}$ \\
Testemunha & $133,00 \mathrm{dA}$ & $130,00 \mathrm{cA}$ & $6,22 \mathrm{dA}$ & $6,35 \mathrm{cA}$ \\
\hline C.V. $(\%)$ & 9,77 & 6,58 & 10,21 & 8,97
\end{tabular}

${ }^{1}$ Médias seguidas pela mesma letra maiúscula na linha e minúscula na coluna, não diferem entre si pelo teste de Duncan, ao nível de $5 \%$ de significância.

Tabela 2 - Área foliar, biomassas fresca e seca da parte aérea (hastes e folhas) de plantas de pessegueiro da cv. Aldrighi inoculadas com três espécies de FMAs e tratadas com AIB, 360 dias após a semeadura. Eldorado do Sul, RS, $2006^{1}$.

\begin{tabular}{lcccccc}
\hline \multirow{2}{*}{ Tratamentos } & \multicolumn{2}{c}{ Área foliar $\left(\mathrm{cm}^{2} /\right.$ planta) } & \multicolumn{2}{c}{ Biomassa fresca $(\mathrm{g})$} & \multicolumn{2}{c}{ Biomassa seca $(\mathrm{g})$} \\
\cline { 2 - 6 } & $+\mathrm{AIB}$ & - AIB & + AIB & - AIB & \multicolumn{1}{c}{+ AIB } & - AIB \\
\hline G. margarita & $717,91 \mathrm{cA}$ & $457,02 \mathrm{cB}$ & $121 \mathrm{cA}$ & $106 \mathrm{cB}$ & $61 \mathrm{bA}$ & $45 \mathrm{cB}$ \\
G. clarum & $823,07 \mathrm{bA}$ & $613,01 \mathrm{bB}$ & $137 \mathrm{bA}$ & $120 \mathrm{bB}$ & $65 \mathrm{bA}$ & $51 \mathrm{bB}$ \\
G. etunicatum & $957,47 \mathrm{aA}$ & $796,90 \mathrm{aB}$ & $166 \mathrm{aA}$ & $139 \mathrm{aB}$ & $73 \mathrm{aA}$ & $62 \mathrm{aB}$ \\
Testemunha & $451,86 \mathrm{dA}$ & $450,25 \mathrm{cA}$ & $103 \mathrm{dA}$ & $108 \mathrm{cA}$ & $38 \mathrm{cA}$ & $37 \mathrm{dA}$ \\
\hline C.V. $(\%)$ & 10,82 & 9,01 & 5,41 & 5,32 & 8,55 & 6,13 \\
\hline
\end{tabular}

${ }^{1}$ Médias seguidas pela mesma letra maiúscula na linha e minúscula na coluna, não diferem entre si pelo teste de Duncan, ao nível de $5 \%$ de significância. 
Plantas inoculadas com $G$. etunicatum apresentaram os maiores incrementos, seguidas pelas inoculadas com G. clarum e G. margarita. A aplicação de AIB não modificou a área foliar e a biomassa fresca e seca das plantas testemunhas, mas quando a aplicação foi feita em plantas inoculadas com FMAs, as mesmas tiveram a sua área foliar e as suas biomassas fresca e seca incrementadas, mesmo no caso das plantas inoculadas com G. margarita. Conforme Bee \& Anderson (1998) a regulação do desenvolvimento da simbiose micorrízica pode ser conseguida através da modificação dos níveis endógenos de fito- hormônios, pela regulação dos níveis de auxinas no fungo e/ou hospedeiro. Kaldorf \& Ludwig-Müller (2000) relatam que modificações no balanço hormonal das plantas, em função do estabelecimento da associação micorrízica, têm sido descritas em diversas espécies vegetais, tanto monocotiledôneas como dicotiledôneas, em função da capacidade dos FMAs de biossintetizar esses fitohormônios, o que, segundo Péret et al. (2008), estimula o desenvolvimento dos vegetais. Por outro lado, conforme observam Cavalcante et al. (2002), a capacidade dos FMAs de regular o balanço hormonal e promover o crescimento dos vegetais está intimamente ligado ao aumento da área foliar, pois esse parâmetro define a taxa de fotossíntese realizada pela planta e a produção de fotoassimilados. Silva et al. (2004), afirmam que o aumento da taxa fotossintética de plantas inoculadas com FMAs está diretamente relacionado ao aumento da área foliar, o que proporciona aumento do crescimento vegetativo e acúmulo de biomassa fresca e seca.

Souza et al. (2000) observam que o efeito das auxinas parece ser independente do efeito dos FMAs, uma vez que essas atuam no incremento da absorção nutricional, enquanto que as auxinas atuam no processo de iniciação radicular. Conforme Hartmann et al. (2001), as plantas não respondem à aplicação de auxinas durante a fase de elongação radicular, o que foi confirmado no presente estudo. Como o AIB foi ineficaz em plantas não inoculadas, mas em presença de FMAs incrementou o desenvolvimento das plantas, fica clara a existência da interação do AIB com os FMAs. Esses resultados estão em concordância com os obtidos em experimentos com citros (Souza, 2000; Souza et al., 2000, 2005), fumo (ShaulKeinan et al., 2002), macieira (Hazarika, 2003) e pimentão (Estrada-Luna \& Davies Junior, 2003).

A inoculação dos FMAs associada à aplicação de AIB aumentou o conteúdo de macronutrientes da parte aérea, exceção feita ao magnésio (Tabela 3).

Os FMAs foram eficientes em incrementar o porcentual de nitrogênio, o fósforo e o potássio, exceção feita à G. margarita sem aplicação de AIB, que apresentou

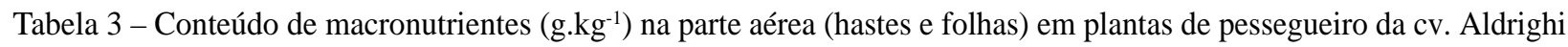
inoculadas com três espécies de FMAs e tratadas com AIB, 360 dias após a semeadura. Eldorado do Sul, RS, $2006^{1}$.

\begin{tabular}{|c|c|c|c|c|c|c|}
\hline \multirow{3}{*}{ Tratamentos } & \multicolumn{6}{|c|}{ Macronutriente $\left(\mathrm{g} \cdot \mathrm{kg}^{-1}\right)$} \\
\hline & \multicolumn{2}{|c|}{$\mathrm{N}$} & \multicolumn{2}{|c|}{$\mathrm{P}$} & \multicolumn{2}{|c|}{$\mathrm{Ca}$} \\
\hline & + AIB & - AIB & + AIB & - AIB & + AIB & - AIB \\
\hline G. margarita & $31,70 \mathrm{bA}$ & $23,80 \mathrm{cB}$ & $2,40 \mathrm{bA}$ & $1,40 \mathrm{cB}$ & $12,90 \mathrm{bA}$ & $12,40 \mathrm{bB}$ \\
\hline G. clarum & $33,20 \mathrm{bA}$ & $30,80 \mathrm{bB}$ & $2,4 \mathrm{~b} 0 \mathrm{~A}$ & $1,90 \mathrm{bB}$ & $12,90 \mathrm{bA}$ & $12,40 \mathrm{bB}$ \\
\hline G. etunicatum & $38,90 \mathrm{aA}$ & $34,10 \mathrm{aB}$ & $2,80 \mathrm{aA}$ & $2,40 \mathrm{aB}$ & $13,00 \mathrm{bA}$ & $12,30 \mathrm{bB}$ \\
\hline Testemunha & $23,60 \mathrm{cA}$ & $23,80 \mathrm{cA}$ & $1,20 \mathrm{cA}$ & $1,30 \mathrm{cA}$ & $17,60 \mathrm{aA}$ & $17,50 \mathrm{aA}$ \\
\hline \multirow[t]{3}{*}{ C.V. $(\%)$} & 9,01 & 8,84 & 5,47 & 7,59 & 8,13 & 7,34 \\
\hline & $\mathrm{K}$ & & & $\mathrm{M}$ & & \\
\hline & + AIB & - AIB & Média & $+\mathrm{AIB}$ & - AIB & Média \\
\hline G. margarita & $24,90 \mathrm{bA}$ & $21,60 \mathrm{cB}$ & $24,30 \mathrm{a}$ & $4,00 \mathrm{~b}$ & $4,00 \mathrm{~b}$ & $4,00 \mathrm{~b}$ \\
\hline G. clarum & $25,10 \mathrm{bA}$ & $22,90 \mathrm{bB}$ & & $4,10 \mathrm{~b}$ & $4,00 \mathrm{~b}$ & \\
\hline G. etunicatum & $26,50 \mathrm{aA}$ & $24,90 \mathrm{aB}$ & & $4,10 \mathrm{~b}$ & $4,10 \mathrm{~b}$ & \\
\hline Testemunha & $22,80 \mathrm{cA}$ & $21,30 \mathrm{cB}$ & $22,00 \mathrm{~b}$ & $6,00 \mathrm{a}$ & $5,60 \mathrm{a}$ & $5,80 \mathrm{a}$ \\
\hline Média & $24,80 \mathrm{~A}$ & $22,70 \mathrm{~B}$ & & 4,50 & 4,40 & \\
\hline C.V. $(\%)$ & 7,17 & 6,94 & & 5,47 & 5,28 & \\
\hline
\end{tabular}

${ }^{1}$ Médias seguidas pela mesma letra maiúscula na linha e minúscula na coluna, não diferem entre si pelo teste de Duncan, ao nível de 5\% de significância. 
comportamento semelhante às testemunhas. Em relação ao cálcio e magnésio, todas as plantas inoculadas com FMAs apresentaram redução dos porcentuais desses elementos, quando feita a comparação com as testemunhas. Dentre as espécies de FMAs, G. etunicatum promoveu as maiores respostas, seguida por G. clarum. O AIB não modificou os porcentuais de macronutrientes das plantas da cv. Aldrighi não inoculadas com FMAs, com exceção dos porcentuais de potássio, para o qual ocorreu incremento em relação às plantas não submetidas à aplicação do AIB. A inoculação de FMAs e a aplicação de AIB atuaram, uma vez mais, sinergicamente, afetando positiva e significativamente os conteúdos foliares de nitrogênio, fósforo e cálcio, inclusive para as plantas tratadas com G. margarita. A interação AIB X FMAs não foi significativa para o potássio e o magnésio.

Mesmo que os FMAs tenham incrementado a absorção de nitrogênio, o maior efeito ocorreu quando houve a associação entre esses e o AIB. Souza (2000), trabalhando com citrangeiro Carrizo, não observou alteração no conteúdo de nitrogênio foliar quando da aplicação de ácido giberélico $\left(\mathrm{AG}_{3}\right)$ associado à inoculação com $G$. intraradices, o que não coincide com os resultados obtidos nesse estudo. Ludwig-Müller (2000) relata que o efeito positivo dos FMAs sobre a absorção de nutrientes de lenta difusão no solo, como o fósforo e o potássio, deve-se à presença do micélio externo dos mesmos, que tem importante papel ao viabilizar maior eficiência dessa absorção em plantas inoculadas. Além disso, segundo relatos de Souza et al. (2000), a aplicação de AIB proporciona um incremento na absorção de fósforo de plantas colonizadas por FMAs, o que coincide com os resultados obtidos nesse trabalho.

Kaldorf \& Ludwig-Müller (2000) relatam que os FMAs não alteraram os níveis de potássio das plantas. Porém, concordando com as afirmações de Souza et al. (2000) que relatam que os FMAs permitem um incremento na absorção desse elemento pelas plantas, os tratamentos com G. clarum e G. etunicatum, com e sem AIB, incrementaram a absorção de potássio, enquanto que o tratamento com G. margarita incrementou a absorção somente quando associado ao AIB. Os autores também observaram que a aplicação do AIB incrementou a absorção de potássio independentemente da presença de FMAs, não ocorrendo interação entre a aplicação de AIB e a colonização das raízes das plantas por FMAs, como no presente estudo. Outra semelhança ao estudo publicado por Souza et al. (2000), foi o fato de que as plantas colonizadas por FMAs apresentaram menores teores de cálcio e de magnésio em relação às testemunhas, o que pode ser atribuído a sua diluição nos tecidos vegetais, em função do incremento do crescimento vegetativo de plantas colonizadas (Souza et al., 2005), ou da capacidade dos FMAs em reduzir a absorção desses macronutrientes (Souza et al., 2005), em função de um efeito tampão proporcionado pelos fungos (Souza, 2000).

Houve interação entre a inoculação dos FMAs e a aplicação do AIB para o porcentual de colonização das raízes, presença de hifas e arbúsculos. A aplicação de AIB em plantas inoculadas com FMAs incrementou o porcentual de colonização e aumentou o número de estruturas de FMAs presentes nas raízes (Tabela 4).

Cabe salientar que os fungos do gênero Gigaspora não formam vesículas intra radiculares, mas sim apresentam células auxiliares extra radiculares. Um aspecto interessante a ser observado é a comparação do estado nutricional das plantas tratadas com AIB em presença e em ausência dos FMAs com os porcentuais de colonização radicular dos tratamentos, uma vez que os maiores incrementos de nitrogênio, fósforo e potássio foram observados nos tratamentos com aplicação de AIB (Tabela 3), justamente onde os maiores porcentuais de colonização aconteceram (Tabela 4). Ferrol et al. (2002) relatam que o aumento da concentração de AIB em raízes colonizadas proporciona aumento na superfície de transferência de água e nutrientes, principalmente fosfatos, que serão usados na fotossíntese, o que acaba promovendo incremento no desenvolvimento vegetal. Além disso, a aplicação exógena de auxinas incrementa o desenvolvimento das ramificações laterais das raízes, aumentando a área de exploração do solo pela planta (Ludwig-Müller, 2000)

Os FMAs aumentam a eficiência de absorção dos nutrientes (Souza et al., 2000, 2005), enquanto o AIB desempenha um papel importante no processo de desenvolvimento inicial da raiz, perdendo a eficácia na fase de elongação radicular (Hartmann et al., 2001). Esses dois efeitos associados poderiam ser responsáveis pelo incremento do crescimento vegetativo. Contudo, como o AIB foi ineficaz em ausência dos FMA, está claro que há um efeito interativo entre ambos os fatores. Diversos autores relatam o aumento do crescimento vegetal associado ao incremento do número de estruturas dos FMAs em raízes tratadas com auxinas, como Souza (2000) e Souza et al. (2000), que trabalharam com citros, Locatelli \& Lovato (2002) e Hazarika (2003), com macieiras, ShaulKeinan et al. (2002), com fumo, e Estrada-Luna \& Davies Junior (2003), com pimentão. 
Tabela 4 - Colonização radicular (\%) e presença de estruturas de FMAs (hifas, vesículas e arbúsculos) encontrados em raízes de plantas da cv. Aldrighi inoculadas com três espécies de FMAs e tratadas com AIB, 360 dias após a semeadura. Eldorado do Sul, RS, $2006^{1}$.

\begin{tabular}{|c|c|c|c|c|c|c|}
\hline \multirow{2}{*}{ Tratamentos } & \multicolumn{6}{|c|}{ Colonização (\%) } \\
\hline & \multicolumn{3}{|c|}{$+\mathrm{AIB}$} & \multicolumn{3}{|c|}{ - AIB } \\
\hline G. margarita & \multicolumn{3}{|c|}{$89,00 \mathrm{bA}$} & \multicolumn{3}{|c|}{$30,33 \mathrm{cB}$} \\
\hline G. clarum & \multicolumn{3}{|c|}{$88,00 \mathrm{bA}$} & \multicolumn{3}{|c|}{$77,00 \mathrm{bB}$} \\
\hline G. etunicatum & \multicolumn{3}{|c|}{$98,00 \mathrm{aA}$} & \multicolumn{3}{|c|}{$90,00 \mathrm{aB}$} \\
\hline Testemunha & \multicolumn{2}{|r|}{$0,00 \mathrm{cA}$} & & \multicolumn{3}{|c|}{$0,00 \mathrm{dA}$} \\
\hline \multirow[t]{3}{*}{ C.V. (\%) } & \multicolumn{2}{|r|}{8,18} & & \multicolumn{3}{|c|}{7,41} \\
\hline & \multicolumn{2}{|c|}{ Hifas } & \multicolumn{2}{|c|}{ Vesículas } & \multicolumn{2}{|c|}{ Arbúsculos } \\
\hline & $+\mathrm{AIB}$ & - AIB & $+\mathrm{AIB}$ & - AIB & $+\mathrm{AIB}$ & - AIB \\
\hline G. margarita & $1,58 \mathrm{bA}$ & $0,78 \mathrm{cB}$ & $0,00 \mathrm{cA}$ & $0,00 \mathrm{cA}$ & $1,22 \mathrm{bA}$ & $0,53 \mathrm{cB}$ \\
\hline G. clarum & $1,60 \mathrm{bA}$ & $1,44 \mathrm{bB}$ & $1,10 \mathrm{bA}$ & $0,70 \mathrm{bB}$ & $1,22 \mathrm{bA}$ & $0,84 \mathrm{bB}$ \\
\hline G. etunicatum & $1,69 \mathrm{aA}$ & $1,57 \mathrm{aB}$ & $1,48 \mathrm{aA}$ & $1,36 \mathrm{aB}$ & $1,61 \mathrm{aA}$ & $1,50 \mathrm{aB}$ \\
\hline Testemunha & $0,00 \mathrm{cA}$ & $0,00 \mathrm{dA}$ & $0,00 \mathrm{cA}$ & $0,00 \mathrm{cA}$ & $0,00 \mathrm{cA}$ & $0,00 \mathrm{dA}$ \\
\hline C.V. $(\%)$ & 5,61 & 7,89 & 6,85 & 9,14 & 8,91 & 8,77 \\
\hline
\end{tabular}

${ }^{1}$ Médias seguidas pela mesma letra maiúscula na linha e minúscula na coluna, não diferem entre si pelo teste de Duncan, ao nível de 5\% de significância.

\section{CONCLUSÕES}

As espécies G. clarum e G. etunicatum, associadas ou não à aplicação de AIB, são eficientes para incrementar o desenvolvimento vegetativo e nutricional de plantas de pessegueiro da cv. Aldrighi, ao passo que G. margarita é eficiente somente quando associada ao AIB.

A aplicação de AIB na fase de elongação celular das raízes é efetiva para aumentar o crescimento vegetativo das plantas da cv. Aldrighi quando associada à inoculação de FMAs.

\section{REFERÊNCIAS BIBLIOGRÁFICAS}

BARKER, S.J.; TAGU, D. The roles of auxins and cytokinins in mycorrhizal symbioses. Journal Plant Growth Regulation, Saint Paul, v.19, p.144-154, 2000 .

BEE, K.A.; ANDERSON, A.J. Regulation of arbuscule formation by carbon in the plant. Plant Journal, New York, v.16, p.523-530, 1998.

CALVET, C.; ESTAÚN, V.; CAMPRIBÍ, A.; HERNÁNDEZ-DORREGO, A.; PINOCHET, J.; MORENO, M.A. Aptitude for mycorrhizal root colonization in Prunus rootstocks. Scientia Horticulturae, Amsterdam, v.9, n.1, p.1-10, 2003.
CAVALCANTE, U.M.T.; MAIA, L.C.; MELO, A.M.M.; SANTOS, V.F. Influência da densidade de fungos micorrízicos arbusculares na produção de mudas de maracujazeiro-amarelo. Pesquisa Agropecuária Brasileira, Brasília, v.37, n.5, p.634-649, 2002.

EMPRESA BRASILEIRA DE PESQUISA AGROPECUÁRIA. Centro Nacional de Pesquisa de Solos. Sistema brasileiro de classificação de solos. Brasília, 1999. 412p.

ESTRADA-LUNA, A.A.; DAVIES JUNIOR, F.T. Arbuscular mycorrhizal fungi influence water relations, gas exchange, abscisic acid and growth of micropropagated chile ancho pepper (Capsicum annuиm) planteds during acclimatization and postacclimatization. Journal of Plant Physiology, Cambridge, v.160, n.9, p.1073-1083, 2003.

FERROL, N.; BAREA, J.M.; AZCÓN-AGUILAR, C. Mechanisms of nutrient transport across interfaces in arbuscular mycorrhizas. Plant and Soil, Dordrecht, v.244, v.2, p.231 - 237, 2002.

FITZE, D.; WIEPNING, A.; KALDORF, M.; LUDWIGMÜLLER, J. Auxins in the development of an arbuscular mycorrhizal symbiosis in mayze. Journal of Plant Physiology, Rockville, v.162, p.1210-1219, 2005. 
GEDERMANN, J.W.; NICOLSON, T.H. Spores of mycorrhizal Endogone extracted from soil by wet sieving and decantinf. Transactions of the British Mycological Society, London, v.46, p.235-244, 1963.

HARTMANN, H.T.; KESTER, E.D.; DAVIES, F.T. Plant propagation: principles and practices. 7.ed. Englewood Cliffs: Prentice Hall, 2001. 702p.

HAZARIKA, B.N. Acclimatization of tissue-cultured plants. Current Science, New York, v.85, n.12, p.17041712, 2003.

KALDORF, M.; LUDWIG-MÜLLER, J. AM fungi might affect the root morphology of maize by increasing indole-3-butyric acid biosynthesis. Plant Physiology, Rockville, v.109, p.58-67, 2000.

LOCATELLI, L.M.; LOVATO, P.E. Inoculação micorrízica e aclimatação de dois porta-enxertos de macieira micropropagados. Pesquisa Agropecuária Brasileira, Brasília, v.37, n.2, p.177-184, 2002.

LUDWIG-MÜLLER, J. Hormonal balance in plants during colonization by mycorrhizal fungi. In: DOUDS, D.D.; KAPULNIK, Y. (Eds.). Arbuscular mycorrhizas: physiology and function. Dordrecht: Kluwer Academic, 2000. p.263-285.

NEMEC, S. Glomus intraradix effects on citrus roostock seedling growth in various potting media. Journal of Agricultural Science, Cambridge, v.118, p.315-323, June 1992.

PÉRET, B.; SVISTOONOFF, S.; LAHOUZE, B.; AUGUY, F.; SANII, L.; DOUMAS, P.; LAPLAZE, L. A role for auxin during actinorhizal symbioses formation? Signaling \& Behavior, New Jersey, v.3, n.1, p.34-35, 2008.
SCHENCK, N.C.; PEREZ, Y.Manual for the identification of VA mycorrhizal fungi. Gainesville: University of Florida, 1988. 240p.

SHAUL-KEINAN, O.; GADKAR, V.; GINZBERG, I.; GRÜNZWEIG, J.M.; CHET, I.; ELAD, Y.; WININGER, S.; BELAUSOV, E.; ESHED, Y.; ATZMON, N.; BEN-TAL, Y.; KAPULNIK, Y. Hormone concentrations in tabacco roots change during arbuscular mycorrhizal colonization with Glomus intraradices. New Phytologist, Cambridge, v.154, p.501-507, 2002.

SILVA, M.A.; CAVALCANTE, U.M.T.; SILVA, F.S.B.; SOARES, S.A.G.; MAIA, L.C. Crescimento de mudas de maracujazeiro-doce (Passiflora alata Curtis) associadas a fungos micorrízicos arbusculares (Glomeromycota). Acta Botanica Brasílica, Manaus, v.18, n.4, p.981-985, 2004.

SOUZA, P.V.D. de. Interação entre micorrizas arbusculares e ácido giberélico no desenvolvimento vegetativo de plantas de Citrange Carrizo. Ciência Rural, Santa Maria, v.30, n.5, p.783-787, 2000.

SOUZA, P.V.D.; AGUSTÍ, M.; ABAD, M.; ALMELA, V. Desenvolvimento vegetativo e morfologia radicular de Citrange Carrizo afetado por ácido indolbutírico e micorrizas arbusculares. Ciência Rural, Santa Maria, v.30, n.2, p.249-255, 2000.

SOUZA, P.V.D.; CARNIEL, E.; SCHIMITZ, J.A.K.; SILVEIRA, S.V. Influência de substratos e fungos micorrízicos arbusculares no desenvolvimento do portaenxerto Flying Dragon (Poncirus trifoliata, var. monstruosa Swing.). Revista Brasileira de Fruticultura, Jaboticabal, v.27, n.2, p.285-287, 2005.

TEDESCO, M.J.; GIANELLO, C.; BISSANI, C.A.; BOHNEN, H.; VOLKWEISS, S.J. Análises de solo, plantas e outros materiais. 2.ed. Porto Alegre: UFRGS, 1995. 174p. (Boletim Técnico, 5). 